\title{
Sequential morphological characteristics of murine fetal liver hematopoietic microenvironment in Swiss Webster mice
}

\author{
Jackline de Paula Ayres-Silva • Pedro Paulo de Abreu Manso • \\ Mariana Rietmann da Cunha Madeira • Marcelo Pelajo-Machado • \\ Henrique Leonel Lenzi
}

Received: 19 March 2010 / Accepted: 5 April 2011 / Published online: 4 May 2011

(C) The Author(s) 2011. This article is published with open access at Springerlink.com

\begin{abstract}
Embryonic hematopoiesis occurs via dynamic development with cells migrating into various organs. Fetal liver is the main hematopoietic organ responsible for hematopoietic cell expansion during embryologic development. We describe the morphological sequential characteristics of murine fetal liver niches that favor the settlement and migration of hematopoietic cells from 12 days postcoitum (dpc) to 0 day post-partum. Liver sections were stained with hematoxylin and eosin, Lennert's Giemsa, Sirius Red pH 10.2, Gomori's Reticulin, and Periodic Acid Schiff/Alcian Blue pH 1.0 and pH 2.5 and were analyzed by bright-field microscopy. Indirect imunohistochemistry for fibronectin, matrix metalloproteinase-1 (MMP-1), and MMP-9 and histochemistry for naphthol AS-D chloroacetate esterase (NCAE) were analyzed by confocal microsco-
\end{abstract}

This work was supported by Fiocruz and CNPq grants.

J. P. Ayres-Silva $(\bowtie) \cdot$ P. P. A. Manso • M. R. C. Madeira •

M. Pelajo-Machado $(\bowtie) \cdot H$. L. Lenzi

Laboratory of Pathology, Instituto Oswaldo Cruz/Fiocruz,

Av. Brasil 4365, Pavilhão Gomes de Faria,

Rio de Janeiro CEP 21040-360, Brazil

e-mail: jackieayres@gmail.com

M. Pelajo-Machado

e-mail: mpelajo@ioc.fiocruz.br

P. P. A. Manso

e-mail: ppmanso@ioc.fiocruz.br

M. R. C. Madeira

e-mail: mrietmann@gmail.com

H. L. Lenzi

e-mail: henrique.lenzi@gmail.com

\section{J. P. Ayres-Silva}

Morphology Sciences Program, Biomedical Sciences Institute,

Universidade Federal do Rio de Janeiro,

Rio de Janeiro, Brazil py. The results showed that fibronectin was related to the promotion of hepatocyte and trabecular differentiation; reticular fibers did not appear to participate in fetal hematopoiesis but contributed to the physical support of the liver after $18 \mathrm{dpc}$. During the immature phase, hepatocytes acted as the fundamental stroma for the erythroid lineage. The appearance of myeloid cells in the liver was related to perivascular and subcapsular collagen, and NCAE preceded MMP-1 expression in neutrophils, an occurrence that appeared to contribute to their liver evasion. Thus, the murine fetal liver during ontogenesis shows two different phases: one immature and mainly endodermic $(<14 \mathrm{dpc})$ and the other more developed (endodermic-mesenchymal; $>15 \mathrm{dpc}$ ) with the maturation of hepatocytes, a better definition of trabecular pattern, and an increase in the connective tissue in the capsule, portal spaces, and liver parenchyma. The decrease of hepatic hematopoiesis (migration) coincides with hepatic maturation.

Keywords Hematopoietic cells · Fetal liver.

Microenvironment - Extracellular matrix · Ontogenesis .

Mouse (Swiss Webster)

\section{Introduction}

During ontogeny, hematopoietic cells home to various organs and settle within defined microenvironments containing favorable factors. These cells remain until the local conditions are modified and then gradually disappear, moving to other subsequent permissive niches that exhibit specific receptors and extracellular matrix (ECM) proteins (Dzierzak 1999; Cumano and Godin 2001).

First, transient hematopoietic cells are generated in the vitelline islands in the yolk sac at 7 days post-coitum (dpc). 
At $8 \mathrm{dpc}$, the intra-embryonary development of blood cells begins in the aorta-gonads-mesonephros region (AGM), and then these hematopoietic stem cells spread to the circulation and are attracted by fetal liver endothelium (Dzierzak and Medvinsky 1995; Dzierzak 1999). At 11 dpc, in the fetal liver, the hematopoietic cells proliferate at an exponential rate and differentiate properly under the influence of the favorable environment created by the hepatic cells (Morrison et al. 1995). These cells secrete extracellular molecules and also express surface molecules that induce the differentiation process in blood cells, thereby creating various proliferation niches. The hepatocytes participate in the cell fate determination of hematopoietic lineages acting as a stroma for blood cells (Arias and Stewart 2002). At this time, hepatic cells express large amounts of $\alpha$-fetoprotein (AFP) and low amounts of albumin (Houssaint 1980; Gualdi et al. 1996; Zaret 2002). On the other hand, hematopoietic cells expand greatly and also secrete large amounts of oncostatin M (OSM) into the extracellular space, inducing the maturation of the hepatocytes. At the same time, AFP expression decreases, whereas albumin expression increases in the hepatocytes, denoting the maturation process (Kinoshita and Miyajima 2002). Hepatocytes express various molecules on their surface and secrete other proteins into the ECM; these substances are favorable to the local arrival of other hematopoietic cell lineages, promoting the progression of the differentiation process (Kinoshita et al. 1999). As soon as the liver becomes more mature, it becomes an unfavorable environment for hemato- poiesis, and, consequently, the blood cells depart from the hepatic sinusoids and move away to the circulation once again. At this time, the bone marrow expresses a stromal-derived factor gradient (SDF-1, CXCL-12), converting the bone marrow into a definitive organ for hematopoiesis in the adult.

The constitution of environments for hematopoiesis in the various organs depends mainly on the local expression of ECM proteins, which define distinct niches favorable to the different blood lineages. Although, some niches have previously been characterized in adult mammal bone marrow, only a small amount of fragmented information exists regarding the hematopoietic environment in the fetal liver. For example, fibronectin has been described as being important for sinusoid development and hepatocyte differentiation in the fetal liver (Sánchez et al. 2000). Matrix metalloproteinases (MMPs) are known to be responsible for the degradation and remodeling of the ECM and are also crucial, during ontogeny, in many processes such as cellular growth, morphogenesis, angiogenesis, and wound repair (Vu and Werb 2000; Pardo and Selman 2005). The presence of MMP1, MMP2, MMP3, MMP7, MMP9, and MMP13 acting as a negative feedback of I, III, and IV collagen synthesis has been detected during fetal liver development (Quondamatteo et al. 1999a, 1999b).

This work has aimed to describe morphologically the sequential characteristics of murine fetal liver niches, with an attempt at discriminating favorable and unfavorable environments for the settlement and migration of hematopoietic cells from $12 \mathrm{dpc}$ to 0 day post-partum.

\begin{abstract}
Fig. 1 Mouse fetal liver at 12 days post-coitum (dpc). a Erythroid lineage cells (thin white arrows): some are still nucleated inside blood vessels. Note the megakaryocytes (black arrows) and some mitotic cells (white arrowheads). Sirius Red pH 10.2 stain. Bar $30 \mu \mathrm{m}$. b Erythropoietic foci (black chevrons) together with some immature myeloid cells: promyelocyte (black arrowhead) and myelocytes (black arrows). Sirius Red pH 10.2 stain. Bar $10 \mu \mathrm{m}$. c Reticular fibers (black arrows) in the submesothelium layer from the capsule and inside the liver. Gomori's reticulin stain. Bar $30 \mu \mathrm{m}$. d PAS staining polysacharides in the capsule (thin black arrow). Periodic Acid Schiff (PAS)/Alcian Blue (AB) pH 1.0 stain. Bar $30 \mu \mathrm{m}$. Insert in d Delicate layer of highly sulfated proteoglycans around cells. PAS-AB pH 1.0 stain. Bar $5.5 \mu \mathrm{m}$
\end{abstract}
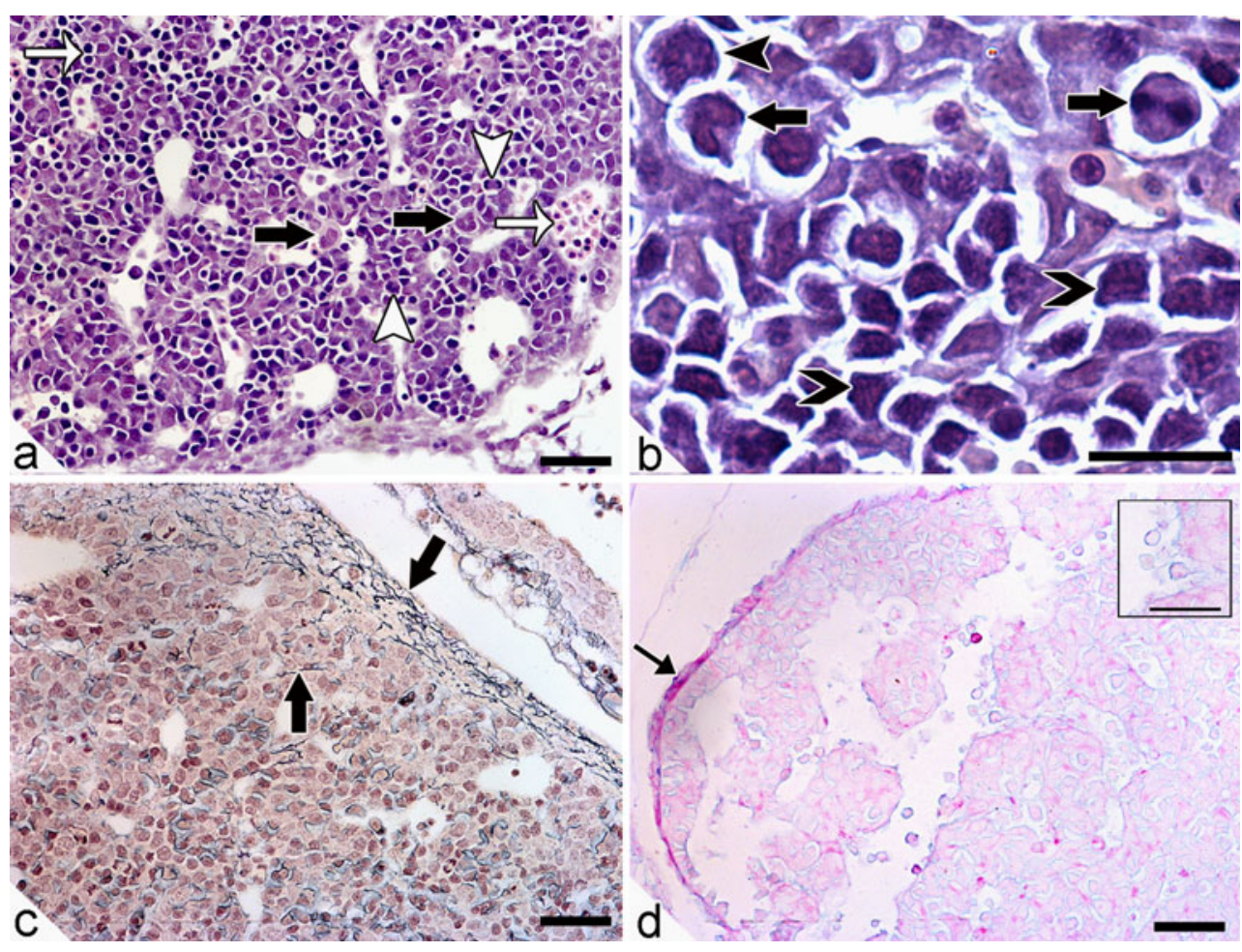


\section{Materials and methods}

Animals

All procedures with mice were performed according to the ethical recommendation of the Ethics Commitee of the Fundação Oswaldo Cruz (Oswaldo Cruz Foundation).

Eight female and eight male Swiss Webster mice from the Animal Laboratory Center of the Fundação Oswaldo Cruz (CECAL) were matched, each couple being housed in individual cages and receiving food and water ad libitum. On the day after breeding, females with a positive vaginal plug defining 0 dpc were individually isolated.

The gestational age was determined from the time of the appearance of the vaginal plug, together with histological parameters as defined in the mouse development atlas of Kaufman (1992). The histological analysis was carried out by comparing several morphological aspects of each animal with the characteristics described in the above-mentioned atlas, because fetal development from the same mother presents a range of developmental timing according to Kaufman (1992) and in our experience.

Newborn mice had their gestational age determined after birth, which was established as 0 day post-partum (0 dpp).

\section{Histological processing}

Eight pregnant female Swiss Webster mice were killed by $5 \% \mathrm{CO}_{2}$ in a closed atmosphere on the following gestational ages: $12,13,14,15,16,17,18 \mathrm{dpc}$, and 0 dpp (one pregnant female/gestational age). Uteri were dissected to individualize the fetuses and placentas. All the fetuses were decapitated, and in those older than $14 \mathrm{dpc}$, the livers were isolated. The material was fixed in Carson's modified Millonig's phosphate-buffered formalin, $\mathrm{pH} 7.4$ (Carson et al. 1973).

The specimens were further histologically processed through increasing ethanol concentrations $(70 \%, 95 \%$, and $100 \%$, for $1 \mathrm{~h}$ each), cleared in xylene (2 hours), and paraffin embedded. Sections of $7 \mu \mathrm{m}$ in thickness were dewaxed with xylene (three times), hydrated with ethanol (three times each in $100 \%, 95 \%, 70 \%$, and 50\%) and stained with hematoxylin and eosin, Lennert's Giemsa (Lennert 1978), Masson's trichrome, Sirius Red at pH 10.2 (eosinophils; Bogomoletz 1980; Luque and Montes 1989), Gomori's Reticulin (reticulin fibers), and Periodic Acid Schiff (PAS)/Alcian Blue (AB) at $\mathrm{pH} 1.0$ and 2.5 (acidic and sulfated glycosaminoglycans).

Other slides were stained with naphthol AS-D chloroacetate esterase (NCAE; Sigma-Aldrich; 91-C Kit) and labeled with Fast Red for the visualization of granulocytic cells.
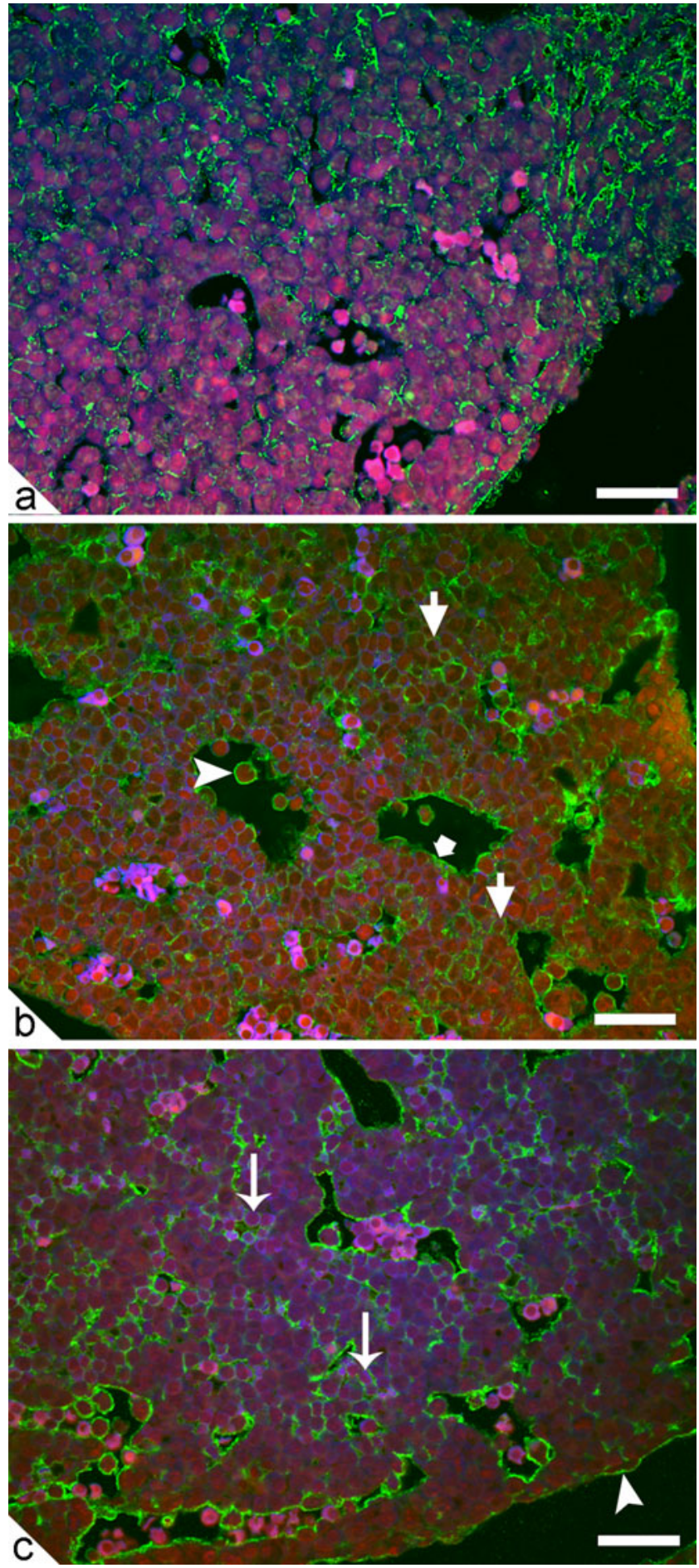

Fig. 2 Mouse fetal liver at $12 \mathrm{dpc}$ (green AlexaFluor488, blue Evans Blue, red DAPI [4,6-diamidino-2-phenylindole]). a Punctiform and discontinuous pattern of fibronectin; the capsule was weakly positive. b Matrix metalloproteinase-1 (MMP-1) expression in endothelial cells of a venule (small fat arrow), in the periphery of some immature and intravascular cells (arrowhead), and in erythroid cells in the parenchyma (arrows). c MMP-9 expression in parenchymal erythroid aggregates (arrows) and in the mesothelial layer (arrowhead). Bars $40 \mu \mathrm{m}$ 
All slides were analyzed by bright-field microscopy (Zeiss Axiovert 200M) with a digital camera (Zeiss Axiocam HRc) or with confocal laser microscopy (LSM 510-META).

\section{Immunofluorescence}

Sections were dewaxed with xylene (three times) and hydrated in decreasing ethanol concentrations (three times each in $100 \%, 95 \%$, and $70 \%$ ) and distilled water. Antigenic retrieval was carried out in $0.01 \mathrm{M}$ citrate buffer pH 6.0 in a microwave oven for $10 \mathrm{~min}$. Subsequently, fetus sections were incubated overnight at $4^{\circ} \mathrm{C}$ with antibodies against fibronectin (Ab-10, RB-077-R7, LabVision), MMP-1 (RB-9225-R7, LabVision), MMP-9 (RB-9234-R7, LabVision), or AFP (SC 8108, Santa Cruz). On the following day, sections were washed in phosphate-buffered saline (PBS) at $\mathrm{pH}$ 7.4 and incubated at $37^{\circ} \mathrm{C}$ for $1 \mathrm{~h}$ with secondary antibody (AlexaFluor488, Invitrogen). Nuclei were then labeled with DAPI (4,6-diamidino-2-phenylindole; Invitrogen; $5 \mathrm{mg} / \mathrm{ml}$ ) for $30 \mathrm{~min}$, and sections were counterstained with Evans Blue $(1: 10,000)$ for $1 \mathrm{~min}$, differentiated in PBS, and mounted with glycerol-paraphenylenediamine (Sigma-Aldrich).
The slides were analyzed by confocal laser microscopy (LSM 510 META, Zeiss); set-ups including an Ar488 laser and BP505-550 filter (AlexaFluor488), HeNe543 laser and LP560 filter (Evans Blue), and 405 laser and LP420 filter (DAPI) were used.

\section{Results}

At $12 \mathrm{dpc}$, fetal liver showed hematopoietic cells with many megakaryoblasts and a large amount of red blood cells at various stages of maturation uniformly distributed among the hepatocytes (Fig. 1a, b). Myelocytes were rarely seen and were localized in the subcapsular regions (Fig. 1a). Subcapsular mesothelium and intrahepatic endothelium presented PAS positivity (Fig. 1d). PAS-AB pH 1.0 stain was seen as a delicate mesh around primitive larger liver portal vessels (Fig. 1d). Furthermore, many mitotic cells in various stages were observed, in contrast to the few apoptotic cells (Fig. 1a, b). Reticular fibers were noticed in the submesothelium layer of the capsule and inside the liver in which thin fibers were found around vessels (Fig. 1c). Some

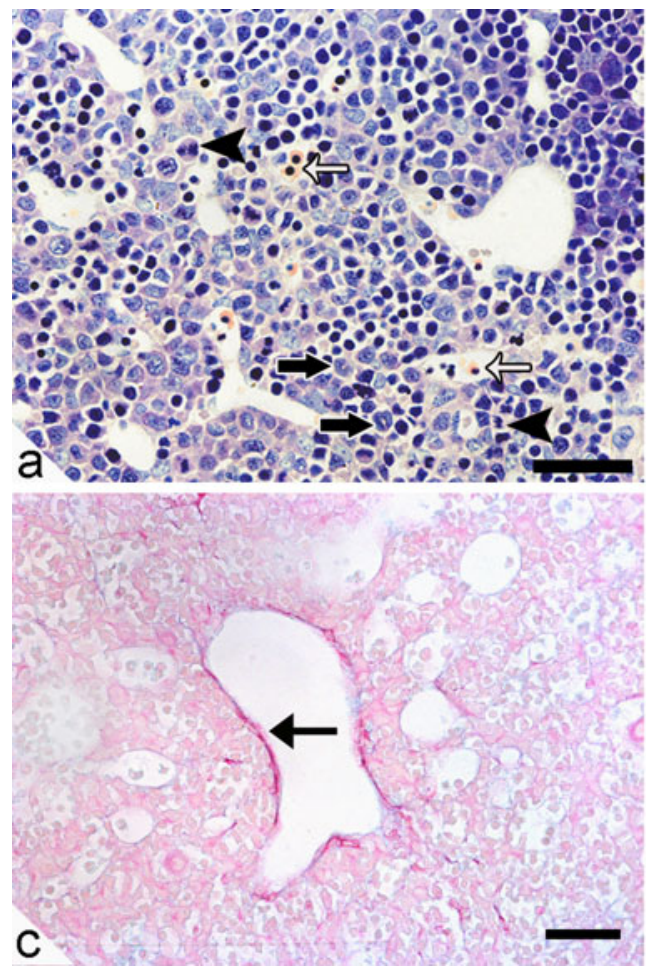

Fig. 3 Mouse fetal liver at $13 \mathrm{dpc}$. a Erythroblasts, normoblasts, myeloblasts, and metamyelocytes (black arrows), megakaryoblasts, megakaryocytes, and many cells in mitosis (black arrowheads). Note the nucleated erythroblasts inside vessels (thin white arrows). Lennert's Giemsa stain. Bar $20 \mu \mathrm{m}$. b High-power magnification showing megakaryocytes (stars), erythroid cells (fat arrow), monocyte (thin arrow), and mitotic figures (arrowheads). Sirius Red pH 10.2

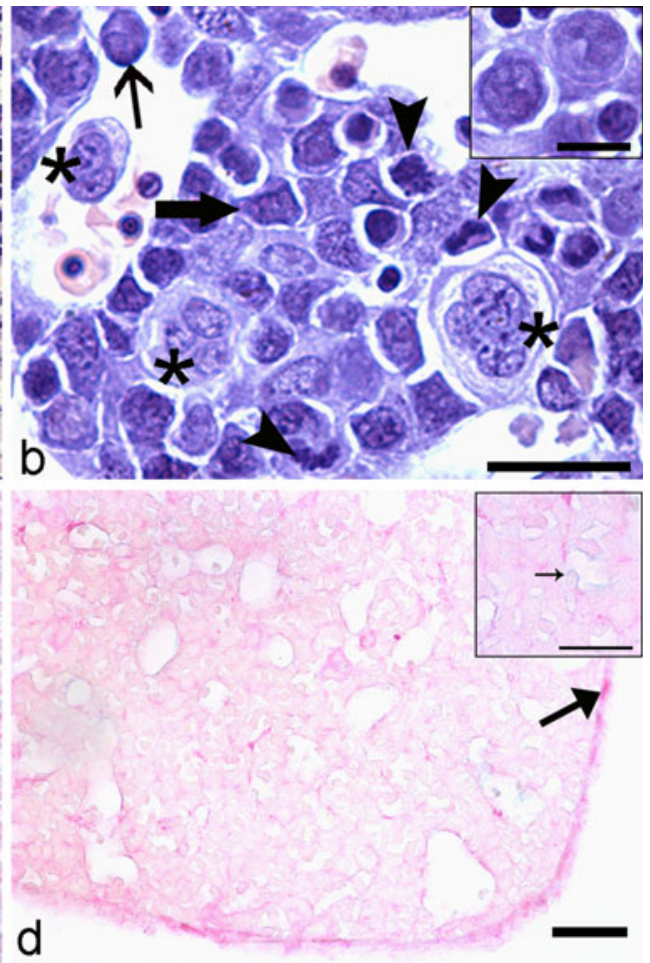

stain. Bar $10 \mu \mathrm{m}$. Insert in b Monoblast (top right) surrounded by erythroid progenitors. Sirius Red pH 10.2 stain. Bar $5 \mu \mathrm{m}$. c PAS reaction around a portal vessel (arrow) and some hepatocytes. Bar $30 \mu \mathrm{m}$. d PAS reaction in the capsule (arrow). PAS-AB pH 1.0 stain. Bar $30 \mu \mathrm{m}$. Insert in d Delicate layer of highly sulfated proteoglycans around cells (small arrow) and endothelium. PAS-AB pH 1.0 stain. Bar $7.5 \mu \mathrm{m}$ 
immature erythroid cells presented extremely thin fibers around them (Fig. 1c).

Fibronectin expression was observed in the sinusoid and venula walls and around the parenchymal and/or hematopoietic cells, displaying a punctiform and discontinuous pattern; the capsule was weakly positive (Fig. 2a).

MMP-1 expression occurred in the periphery of cells, probably from the erythroid lineage, and appeared a little more intensely in venulae and in some immature and intravascular cells (Fig. 2b). MMP-9 was more evident in vessel walls and surrounding some groups of small cells, probably of erythroid lineage, whereas its expression in the mesothelial layer was weaker (Fig. 2c).

At $13 \mathrm{dpc}$, immature erythroid cells were predominant, with megakaryoblasts, megakaryocytes, and many cells in mitosis (Fig. 3a, b). Vascular and trabecular vessels were better defined, and more hematopoietic cells were present inside the liver (Fig. 3a, b). PAS staining continued to be expressed in the conjunctive tissue, around vessel walls, and in the capsule (Fig. 3c, d). Proteoglycans positive for PAS-AB pH 1.0 were detected in the capsular mesothelium and in the venular endothelium (Fig. 3c, d). Reticular fibers were still noted in the capsular submesothelial cells. Red blood cells were negative to Gomori's reticulin. Nucleated red blood cells continued to be present in the circulation (Fig. 3a, b).

Immunostaining for fibronectin was seen in endothelial and subendothelial cells, presenting a more exacerbated punctiform pattern than that at $12 \mathrm{dpc}$. It was also detected with higher intensity in some small cellular groups (seemingly erythroid) and with weak linear expression in the subcapsular region (Fig. 4a).

Expression of MMP-1 was seen in the cytoplasm of erythroid cells but not in the capsule (Fig. 4b). MMP-9 was more disperse than at the previous time point, appearing throughout the parenchyma and occurring in the venula walls with a granular pattern (Fig. 4c). It was not detected in the capsule.

At $14 \mathrm{dpc}$, the fetal liver was still profusely occupied by erythroid cells, but they were more mature, and inside the vessels, red blood cells without a nucleus predominated (Fig. 5a). Megakaryocytes were also more differentiated and presented a weak reaction to PAS-AB pH 2.5 or 1.0 (Fig. 5b). Intrahepatic venulae and descontinuous subendothelial cells were PAS-positive (Fig. 5b). The surface of the venular endothelium and mesothelium exhibited a linear pattern of PAS-AB pH 1.0 (Fig. 5b). The mesothelium, under a superficial layer of proteoglycan, presented a light PAS reaction. Gomori's reticulin was negative (Fig. 5c).

Fibronectin was only seen in vessel walls including the sinusoids, being stronger in portal veins in which it was
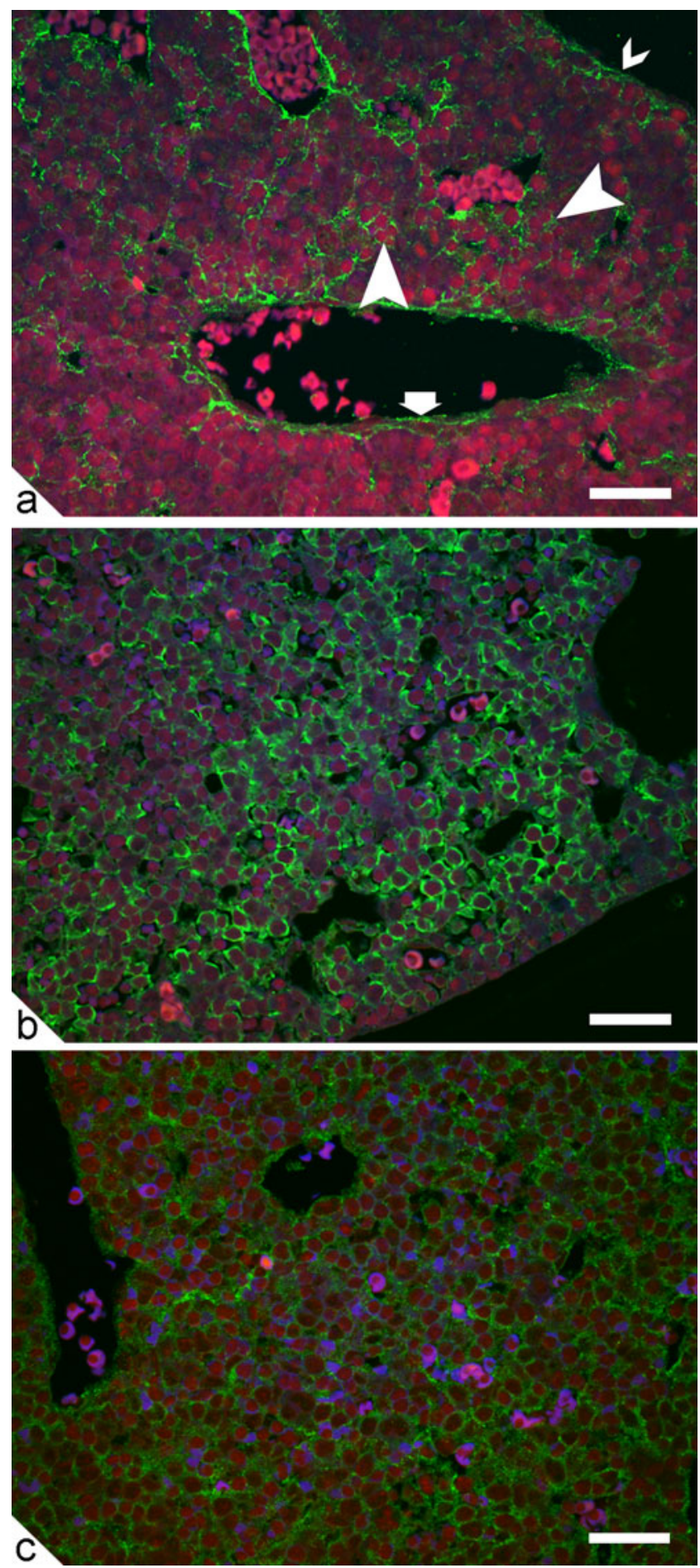

Fig. 4 Mouse fetal liver at $13 \mathrm{dpc}$ (green AlexaFluor488, blue Evans Blue, red DAPI). a Fibronectin in erythroid cells (arrowhead), in endothelial (fat arrow) and subendothelial cells, and in the subcapsular region (chevron). b MMP-1 in the cytoplasm of erythroid cells in the parenchyma and in blood vessels. c MMP-9 dispersed through the parenchyma and presented in venulae walls with a granular pattern. Bars $40 \mu \mathrm{m}$

concentrically arranged (Fig. 5d), whereas MMP-1 and MMP-9 were negative. 
Fig. 5 Mouse fetal liver at 14 dpc. a Intermediary normoblasts, erythroid cells (some with a nucleus), megakaryoblasts (arrows) and monocytes (arrowhead). Hematoxylin and eosin (HE) stain. Bar $30 \mu \mathrm{m}$ (insert $10 \mu \mathrm{m}$ ). b PAS-positive reaction in hepatocytes around intrahepatic venulae (arrow) and discontinuous subendothelial cells. Note the mesothelium with a light PAS reaction, and the linear pattern of $\mathrm{AB} \mathrm{pH} 1.0$ proteoglycans in the surface of the venular endothelium and around cells. PAS-Alcian Blue pH 1.0 stain. Bar $30 \mu \mathrm{m}$. c Note some reticular fibers inside the liver (arrows), but the capsular region is without reticular fibers. Gomori's reticulin stain. Bar $30 \mu \mathrm{m}$. d Fibronectin in sinusoids, in portal veins, and in the subcapsular region (green AlexaFluor488, red Evans Blue, blue DAPI). Bar $40 \mu \mathrm{m}$. e Myeloid cells expressing naphthol AS-D chloroacetate esterase (NCAE) in the parenchyma (green Gill's 3 hematoxylin, red Fast Red). Bar $40 \mu \mathrm{m}$. Insert in e Myeloid cells expressing NCAE in the subcapsular region (green Gill's 3 hematoxylin, red Fast Red). Bar $20 \mu \mathrm{m}$
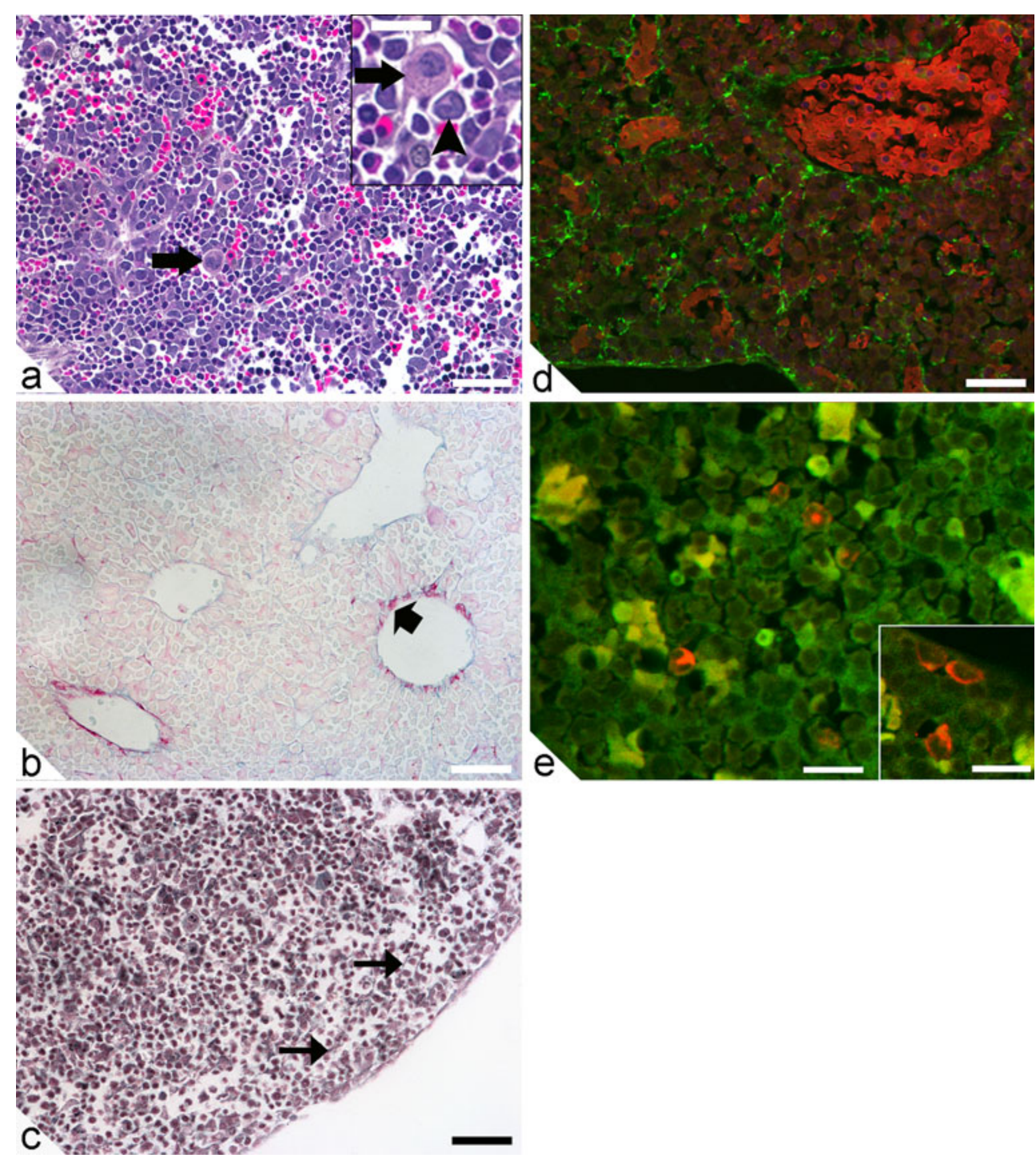

Granulocytes were histochemically demonstrated with NCAE close to the capsule and dispersed in the parenchyma (Fig. 5e).

At $15 \mathrm{dpc}$, the liver was still highly settled by erythroid cells and also showed an increase in megakaryocytes (Fig. 6a). Nucleated red blood cells were rarely seen inside the sinusoids (Fig. 6a). From this moment onward, some hepatocytes with PAS granules were noticed. They were located distant from each other or were beginning to form trabeculae (Fig. 6b). Immature neutrophil islands were sporadically observed, especially in the subcapsular region. Eosinophils were noticed for the first time. They lay close to the major branches of the portal vein. Some mitotic cells were still seen. Venulae continued to exhibit a discontinuous linear PAS pattern (Fig. 6b). We did not detect any reaction with Gomori's reticulin (Fig. 6c).

Fibronectin expression was intense with a granular pattern around venulae, forming a concentric arrangement. It was also positive in the conjunctive of the submesothelial capsule, in the sinusoid walls, delimiting hepatic trabeculae with many erythroid cells (Fig. 6d). Both MMP-1 and MMP-9 were negative.

At $16 \mathrm{dpc}$, the presence of megakaryocytes and erythroid cells was still intense, but the erythroid lineage cells were more mature with many normoblasts. The granulocyte populations, predominantly neutrophils with few eosinophils, were seen in all extension of the subcapsular region and in the stroma around large portal veins (Fig. 7a). Hepatocytes were more mature with a marked amount of PAS-positive granules (glycogen; Fig. 7b) and low expression of AFP (Fig. 8d). Some isolated spherical cells with basophilic cytoplasm and metachromasy following Giemsa staining indicated the possible presence of mast cell precursors. Eosinophils were sparsely seen inside the parenchyma and were always mature, without eosinopoietic foci (Fig. 7a). Some of the large cells with a doughnutshaped nucleus seemed to be granulocyte-macrophage cells. A monocytopoiesis focus was also seen in the 
Fig. 6 Mouse fetal liver at 15 dpc. a Intense erythroid and megakaryocytic proliferation. HE stain. b Hepatocytes with PAS granules (arrow) near sinusoids. PAS-AB pH 1.0 stain. c Hepatic parenchyma and capsulae without reticular fibers. Gomori's reticulin stain. d Fibronectin in the capsular submesothelial layer, sinusoids, and venula wall (green AlexaFluor488, blue Evans Blue, red DAPI). Bars $30 \mu \mathrm{m}$

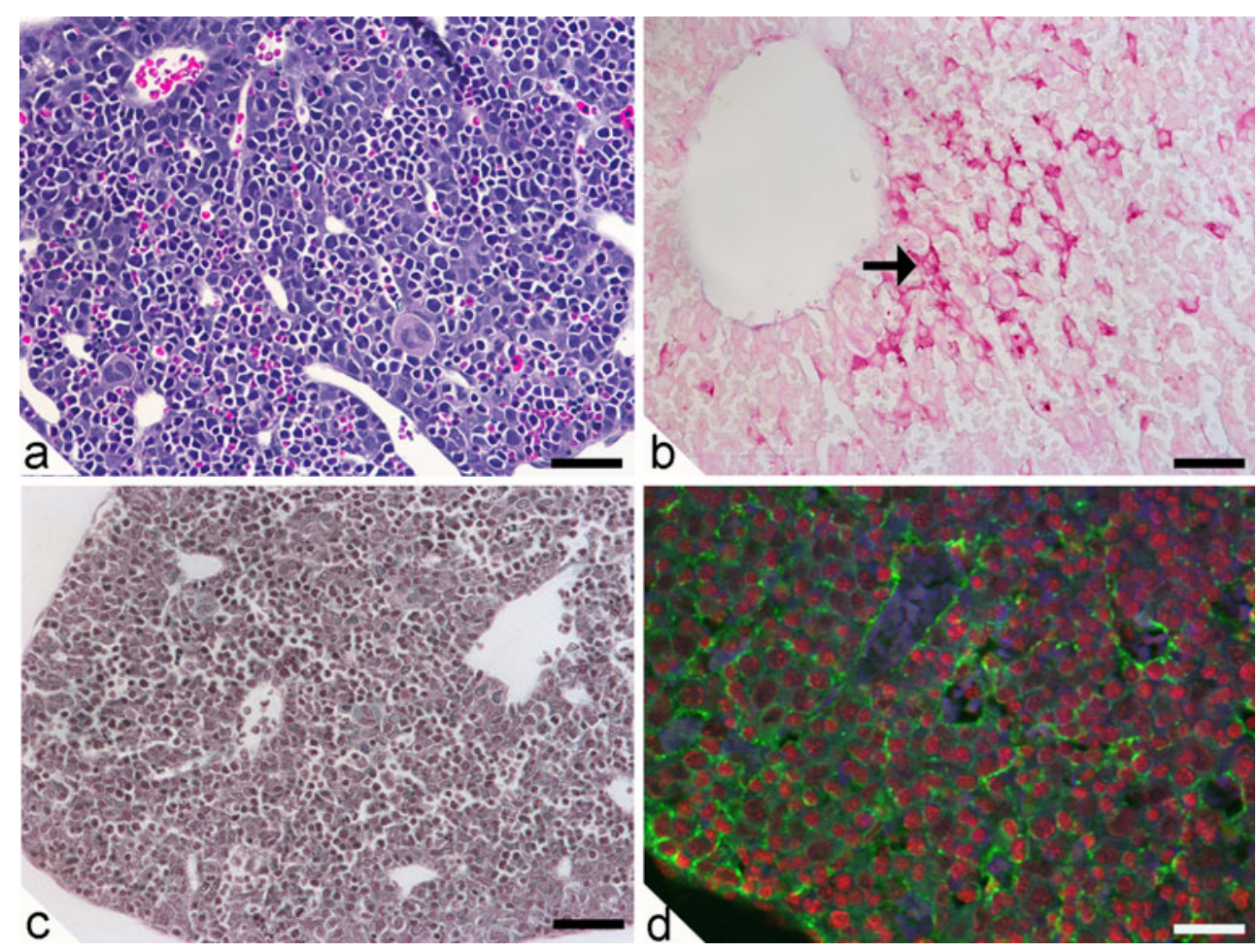

subcapsular region. Portal veins were stained only with Masson's trichrome and did not express reticular fibers as shown by Gomori's reticulin (Fig. 7c). Mesothelial cells

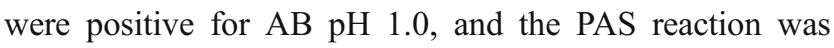
more reduced in the venula walls (Fig. $7 b$ ).

Fibronectin expression at $16 \mathrm{dpc}$ was lower than that at $15 \mathrm{dpc}$ in the wall of venulae, in the submesothelial conjunctive tissue of the capsule, and within the whole parenchyma, showing a dotted pattern in sinusoid walls (Fig. 8c).

The expression of NCAE easily allowed the visualization of the preferential location of neutrophil foci in the subcapsular region (Fig. 8a), and MMP-1 expression was intense in the cytoplasm of neutrophils (Fig. 8b). MMP-9 was negative.

At $17 \mathrm{dpc}$, the erythroid lineage was significantly more highly differentiated, showing many polychromatic and orthochromatic normoblasts that were evenly distributed throughout the liver, sometimes forming small aggregates around portal veins. The relative density of the erythroid cells when compared with hepatocytes was lower than that observed in livers from previous stages. An expressive reduction was also noted in the number of megakaryocytic cells, and the red blood cells inside the circulation were enucleated. We also noticed monocyte clusters with undifferentiated cells presenting an immunoblastic-like aspect around the large portal veins (Fig. 9a, b). Hepatocytes were more mature, with many vacuolizations and PAS-positive granules inside them, forming distinct trabeculae.
Fibronectin expression had a granular pattern in the venular and sinusoidal walls and in the submesothelial conjunctive tissue of the capsule (Fig. 9c).

Neutrophils were clearly discernable because of their high expression of NCAE, and immunostaining for MMP-1 was intense in neutrophils and was occasionally also located around vessels.

At $18 \mathrm{dpc}$, erythroid and megakaryocytic lineages showed a similar pattern to that at $17 \mathrm{dpc}$, but with greater rarefaction of the hemopoietic component (Fig. 10a). Neutrophil and eosinophil lineages were more frequent, mainly in the large portal spaces and in the subcapsular region (Fig. 10a). These cells were also seen in small portal spaces in which collagen began to be deposited. Some neutrophils and eosinophils were also sparsely distributed in the parenchyma (Fig. 10a). Hepatocytes were more mature, with glycogen granules (Fig. 10b). Reticular fibers were noted in the capsule, in large portal spaces, and occasionally in the parenchyma (Fig. 10c). The mesothelium was positive for $\mathrm{AB} \mathrm{pH}$ 1.0.

MMP-1 was intense in the cytoplasm of neutrophils (Fig. 10e). Fibronectin was less intense, with a granular pattern in the venular and sinusoidal walls and in the submesothelial connective tissue of the capsule (Fig. 10d).

At $0 \mathrm{dpp}$, erythroid cells formed small isolated foci throughout the liver; these foci consisted of basophilic, polychromatic, and mainly orthochromatic normoblasts, and apoptotic cells were sometimes seen (Fig. 11a). The number of megakaryocytic cells was higher than at $18 \mathrm{dpc}$, with many megakaryoblasts. Myeloid cells, especially 

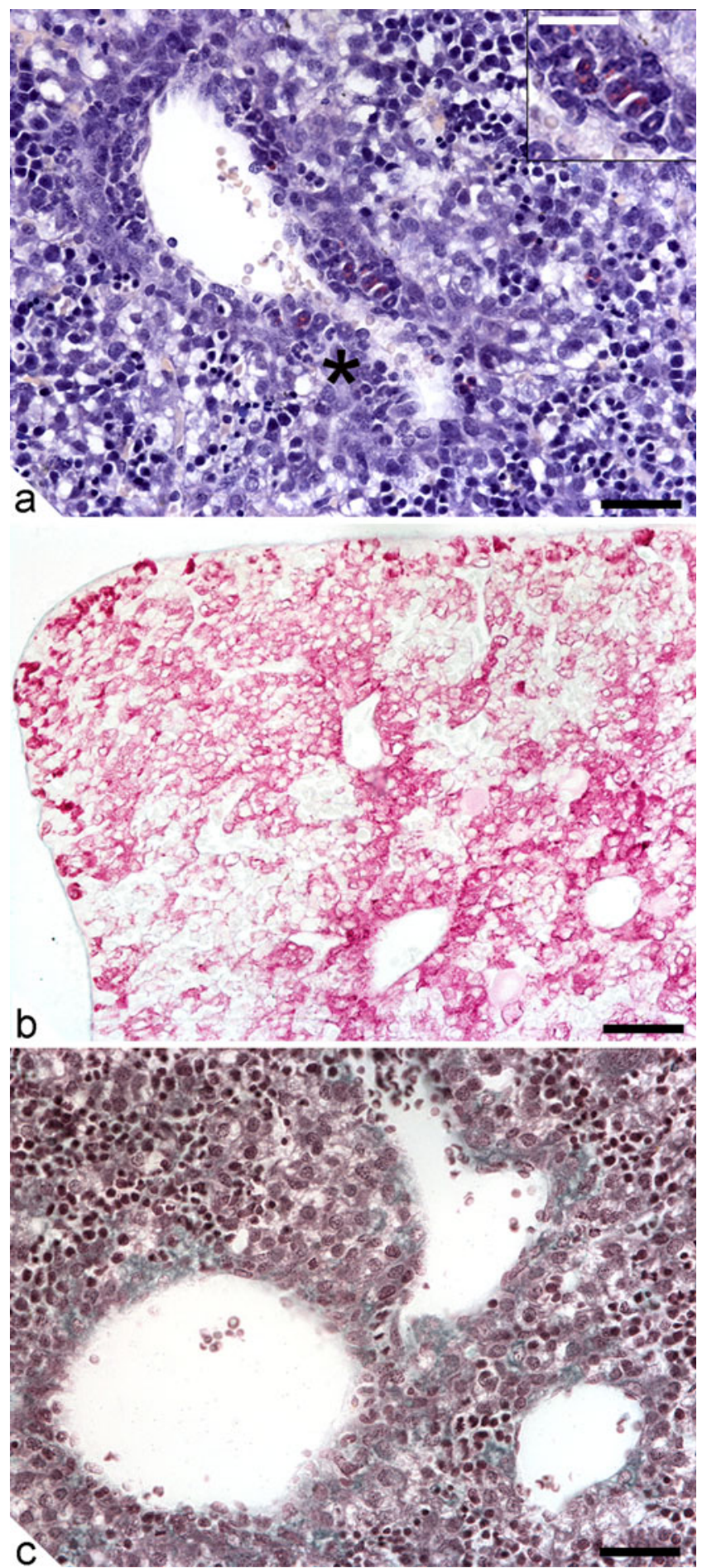

Fig. 7 Mouse fetal liver at $16 \mathrm{dpc}$. a Erythroid lineage cells with many normoblasts. Mature neutrophilic and eosinophilic cells (star) in the conjunctive tissue around the large portal veins. Sirius-Red $\mathrm{pH} 10.2$ stain. Bar $30 \mu \mathrm{m}$. Insert in a Myeloid focus with many eosinophils (red). Sirius-Red pH 10.2 stain. Bar $7.5 \mu \mathrm{m}$. b Mature hepatocytes with a marked amount of PAS-positive granules of glycogen. PAS-AB pH 1.0 stain. Bar $30 \mu \mathrm{m}$. c Hepatic parenchyma and large vessels showing no silver impregnation. Gomori's reticulin stain. Bar $30 \mu \mathrm{m}$ neutrophils, were more numerous, displaying several foci mainly in the large portal spaces and in the subcapsular region (Fig. 11b). Eosinophils were less frequent than at 18 $\mathrm{dpc}$, and immunoblast-like cells (uncharacterized immature cells) were sparse throughout the parenchyma. Mast cells were rare and scattered in the parenchyma or located in the portal spaces. Isolated monocyte foci were detected more clearly in the subcapsular region. An impressive increase occurred in the number of reticular fibers, making a threedimensional network in the parenchyma and exhibiting higher density in the portal and capsular regions (Fig. 11c). Hepatocytes showed a diffuse microgoticular steatosis with PAS-positive neutral glycoprotein surrounding fat vacuoles (Fig. 11d). No collagen increase was observed in the connective tissue of the intrahepatic venulae and portal spaces (Fig. 11b).

Fibronectin expression was similar to that observed in other developmental stages, showing a granular pattern in the venular and sinusoidal walls and in the submesothelial connective tissue of the capsule (Fig. 11e). MMP-1 was still intense in the cytoplasm of neutrophils (Fig. 11f).

Relevant negative controls for the immunofluorescent staining are shown in Fig. 12.

Table 1 summarizes the main molecules analyzed in this work, and Table 2 presents a semiquantified analysis of myeloid, megakaryocytic, and erythroid lineages during murine fetal liver development.

\section{Discussion}

Here, we describe the development of fetal liver as a hematopoietic organ from $12 \mathrm{dpc}$, when the primordium begins, to the first day of birth ( $0 \mathrm{dpp})$. The results show that: (1) fetal liver, during ontogeny, presents two basic phases, the one being an immature phase, which is predominantly endodermic (before $14 \mathrm{dpc}$ ), and the other being a more mature phase (endodermic-mesenchymal) during which hepatocyte maturation, a better definition of trabecular and vascular patterns, and an increase in the mesenchymal connective tissue in the capsule, in the venular walls, and in the parenchyma interstitium occur (after $15 \mathrm{dpc}$ ); (2) the hepatocytes act as the fundamental stroma for the erythroid lineage (trabecular hematopoiesis) in the immature fetal liver (endodermic stromal support); (3) the extracellular molecule fibronectin appears to be more closely related to hepatocyte maturation and the definition of the trabecular pattern of the fetal liver; (4) reticulin fibers, which biochemically correspond to collagen type III or fibronectin or to undefined non-collagenic glycoproteins (Unsworth et al. 1982), are not relevant to fetal hematopoiesis and arise only in the late period of the more mature phase of the fetal liver; (5) the appearance of 
Fig. 8 Mouse fetal liver at 16 dpc. a NCAE in neutrophil foci in the subcapsular region (green Gill's 3 hematoxylin, red Fast Red). b MMP-1 expression in the cytoplasm of neutrophils (green AlexaFluor488, blue Evans Blue, red DAPI). c Granular fibronectin expression in the venulae and parenchyma (green AlexaFluor488, blue Evans Blue, red DAPI). d Low expression of $\alpha$-fetoprotein (green AlexaFluor488, red DAPI). Bars $30 \mu \mathrm{m}$
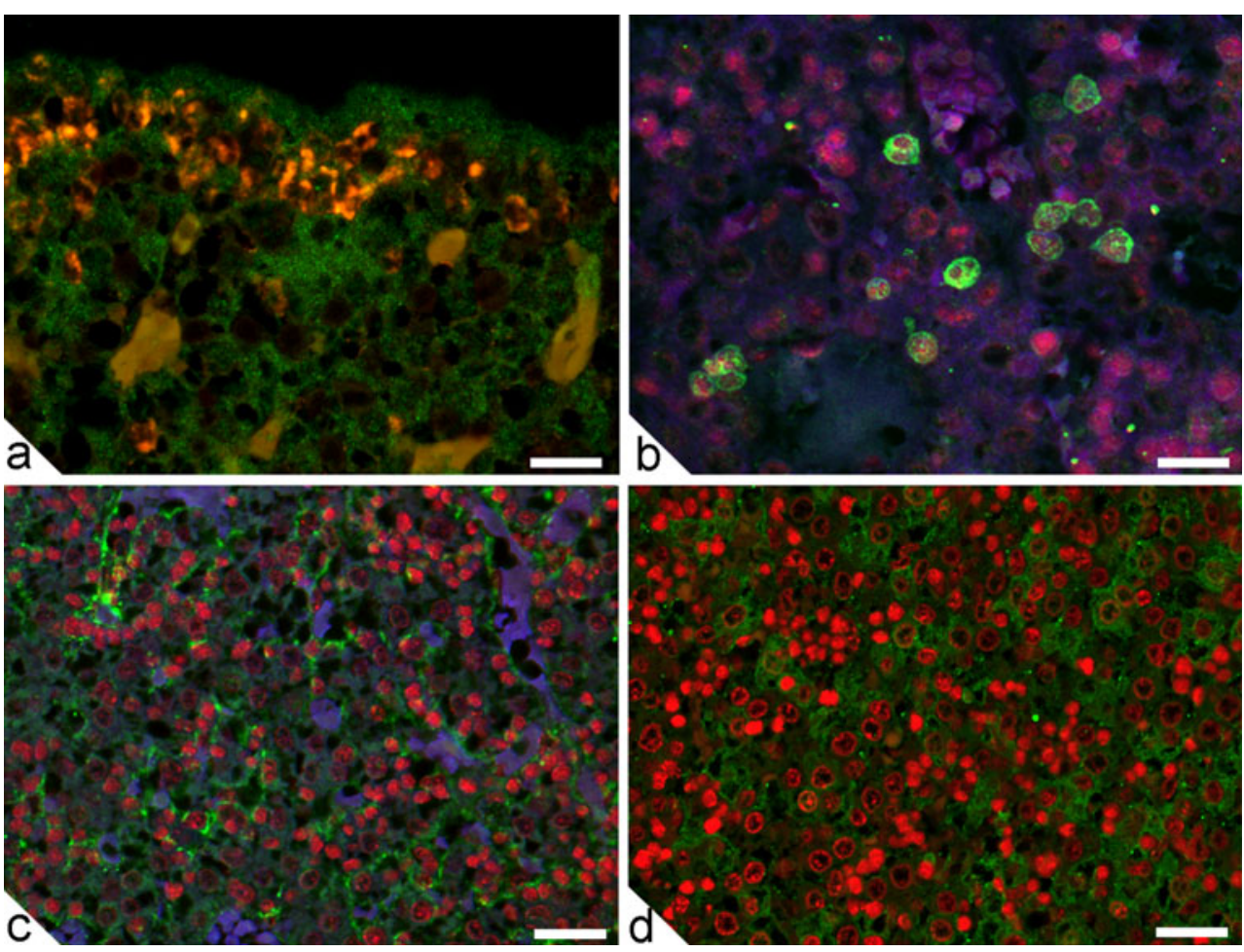

myeloid cells in the fetal liver is related to an increase of the mesenchymal stroma, especially around the thick branches from the portal vein; (6) NCAE is the best histochemical marker for the more immature neutrophils foci, whereas the mature neutrophils are positive for MMP1; (7) the decay of hepatic hematopoiesis (uninhabitable phase) is coincident with hepatic maturity.

In the literature, only a few studies can be found that concern the interaction between hematopoietic cells with hepatic endothelial and stromal cells, and that stress the importance of this kind of study to a better understanding of hematopoietic embryology. This study has therefore dealt with the sequential appearence of hematopoietic cells, hepatocyte maturation, metalloproteinase expression by hematopoietic cells, and ECM composition during liver development.

At $12 \mathrm{dpc}$, many progenitor cells begin to home toward the fetal liver in which they then locally differentiate into erythroid and megakaryocytic cells. At this time, hepatocytes are still immature and act as stromal cells for the hematopoietic lineage until $18 \mathrm{dpc}$.

The fetal liver follows the four main morphological steps of other lymphoid and lymphohematopoietic organs: (1) the mesenchymal-endodermic pre-hematopoietic phase; (2) hematopoiesis establishment; (3) differentiation and specialization of the organ; (4) expansion or the terminal phase (Lenzi and Lenzi 1986). Here, we have sequentially described some of these development steps in vivo, integrating the hematopoietic process with the components and arrangement of ECM. The expression of collagens and proteoglycans is low but constant from 12 to $18 \mathrm{dpc}$. Fibronectin expression is higher and more constantly expressed, especially around vessels, in the wall of veins and sinusoids, being a marker of blood vessels and hepatocyte trabeculae maturity. Sánchez et al. (2000) have shown that only fibronectin facilitates the formation of elongated cord-like structures, reminiscent of liver plate organization, modulating fetal hepatocyte morphology, growth, and differentiation. Our data do not indicate that the output of hematopoietic mature cells from the liver is related to tissue fibronectin levels, in view of its constant expression during the various periods of liver development. In vitro, the integrin VLA4 (very late antigen 4) mediates the adhesion of hemopoietic progenitors to bone marrow stroma through an interaction with its ligands VCAM-1 (vascular cell adhesion molecule 1) and the CS1 moiety of fibronectin, as observed by Craddock et al. (1997b); however, these authors have observed that, in contrast to VCAM-1, the CS1 moiety of fibronectin is not a significant ligand in VLA4-mediated progenitor trafficking in vivo. Hence, its major role seems to be devoted to hepatocyte maturation, and not to hematopoietic cell adherence in the fetal liver.

The appearance of reticulin fibers in the fetal liver, after a transitory phase, is belated, occurring after $17.5 \mathrm{dpc}$, as has also been seen by Amenta and Harrison (1997). The scarcity of fibers in the early periods of liver development is probably advantageous for hematopoiesis, favoring intrahepatic cell mobility and attachment to hepatocytes, which seem to act as the main stromal cells to hematopoi- 


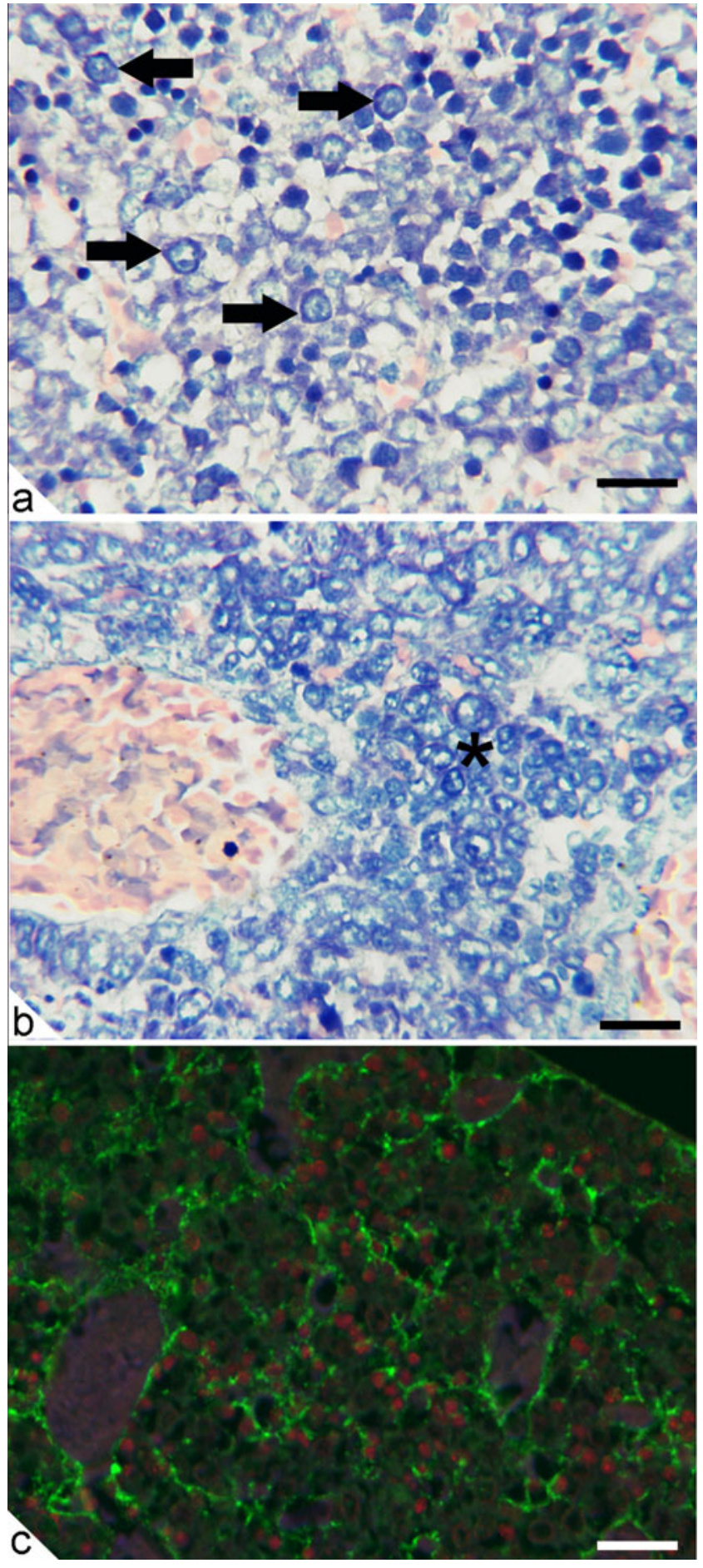

Fig. 9 Mouse fetal liver at $17 \mathrm{dpc}$. a Lower relative density of erythroid cells compared with previous stages, showing predominance of normoblasts. Note the presence of immunoblastoid cells (arrows). Lennert's Giemsa stain. b Monocyte cluster (star) with undifferentiated cells around a large portal vein. Lennert's Giemsa stain. Bars $10 \mu \mathrm{m}$. c Fibronectin expression in the venulae walls, in the capsular submesothelial layer, and in perivascular small erythroid cells (green AlexaFluor488, blue Evans Blue, red DAPI). Bar $30 \mu \mathrm{m}$

etic cells. The late appearance of the collagen network appears to be involved with the requirement for a physical scaffold to support the gradual and vast hepatic enlargement and the maturation of hepatocytes. Brill et al. (2002) have observed that adult hepatocyte ECM better supports the expression of adult genes, whereas fetal hepatocyte ECM induces the expression of fetal genes.

Considering the scarcity of ECM in the liver, we suggest that fetal hematopoiesis is essentially controlled by paracrine cell-cell contact, rather than being under the influence of the ECM. Indeed, hematopoietic environments usually have a tiny amount of fibrillar ECM and are more dependent on proteoglycan components. Brill et al. (2002) have provided evidence that heparin sulfate is the active element in adult ECM, and chondroitin sulfate in fetal ECM.

We have demonstrated that erythroid cells appear in the fetal liver at $12 \mathrm{dpc}$ and proliferate in clusters among hepatocytes (trabecular erythopoiesis), being sometimes difficult to discriminate in the liver parenchyma from the hematopoietic cells. The erythroid lineage evolves gradually from nucleated to anucleated cells only after $14 \mathrm{dpc}$.

In humans, megakaryocytic cells are seen near erythroid cells in the sinusoids and hepatic hilum from 6th and 7th weeks, respectively (H.L. Lenzi, unpublished). Zamboni (1965a, 1965b) has observed megakaryocytes after 12 weeks, when hepatic hematopoiesis is effective with all lineages. In mouse, we have detected these cells near hepatic sinusoids from $12 \mathrm{dpc}$. At $15 \mathrm{dpc}$, the number of megakaryocytic cells decreases, and these cells persist at low levels until $18 \mathrm{dpc}$. Megakaryocytes are important in bleeding hemostasis, leaving platelets in the blood system. Hamada et al. (1998) and Lane et al. (2000) have shown in vitro the effect of SDF-1 on megakaryocyte migration binding to CXCR4. This mechanism might contribute to the homing process during ontogeny, when these cells migrate many times, from the vitelline yolk to the fetal bone marrow.

Neutrophils and eosinophils have been detected in the fetal liver from 12 dpc. At 15-17 dpc, they are seen around and near large sinusoids. From 16-18 dpc, eosinophils are intermixed with many neutrophils. This late detection of myeloid cells in the fetal liver can be explained by the following mechanisms: (1) the stem cells committed to both cellular lineages might quiescently persist in the fetal liver until a favorable microenvironment arises in the subcapsular region and around portal vein walls, which express ECM-mesenchyma dependence; or (2) this type of stem cell arrives late in the fetal liver, coming from an undefined organ. This second hypothesis is unlikely, because hematopoiesis stops at $11.5 \mathrm{dpc}$ in the yolk sac and placenta and at $12 \mathrm{dpc}$ in the AGM.

Thomas and Yoffey (1964), Enzan et al. (1978), Emura et al. (1983), and Sohn et al. (1993) have demonstrated granulocytic cells in human fetal liver. However, this has 
Fig. 10 Mouse fetal liver at 18 dpc. a Neutrophilic and eosinophilic lineages associated with late erythroblasts in large portal spaces and in the subcapsular region. Sirius Red pH 10.2 stain. Bar $30 \mu \mathrm{m}$. Insert Some eosinophils (red). Sirius Red pH 10.2 stain. Bar $7.5 \mu \mathrm{m}$. b Mature hepatocytes showing high reactivity to PAS (arrow). PAS-AB pH 1.0 stain. Bar $30 \mu \mathrm{m}$. c Reticular fibers appear in the capsule (arrow). Gomori's reticulin stain. Bar $30 \mu \mathrm{m}$. d Fibronectin expression in sinusoids and in the connective submesothelial tissue (green AlexaFluor488, blue Evans Blue, red DAPI). Bar $30 \mu \mathrm{m}$. e MMP-1 in the cytoplasm of neutrophils in the large portal spaces (green AlexaFluor488, blue Evans Blue, red DAPI). Bar $30 \mu \mathrm{m}$
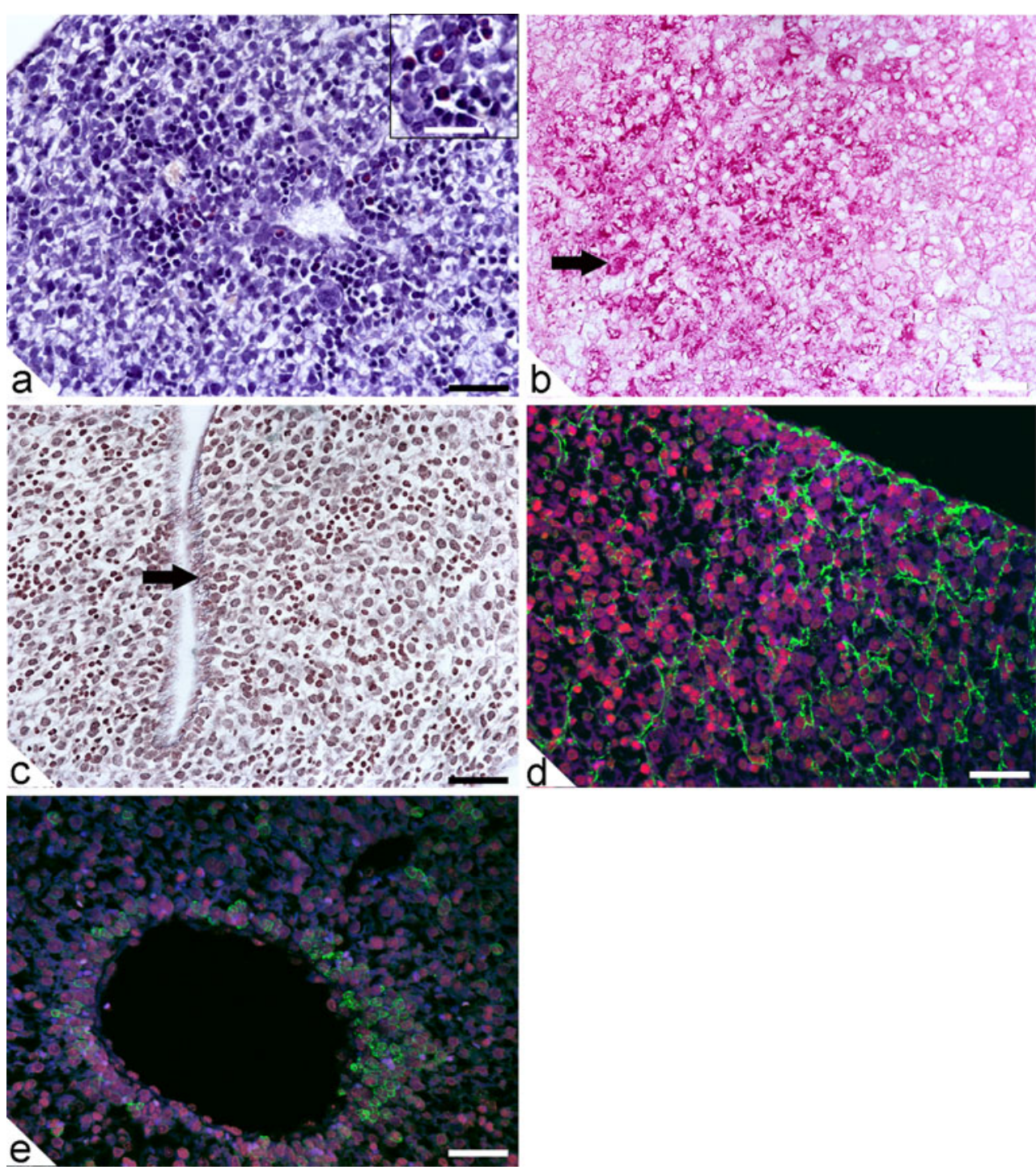

previously not been clearly described in mice. Enzan et al. (1978) have reported granulocytic cells such as neutrophils and eosinophils after the cell culture of human fetal liver from 10 to 13 weeks of gestation and have drawn attention to a topographic association between the various stages of these cells and the hepatic mesenchyma.

Here, we have described the presence of neutrophilic granulocytes in the connective stroma (collagenic and reticular fibers) in the capsule and in the subcapsular region of fetal mouse liver from 14 to $17 \mathrm{dpc}$, as shown by NCAE. After $15 \mathrm{dpc}$, an increase of neutrophilic granulocytes and the appearance of eosinophils have been observed in connective tissue around the wall of the large vessels of the portal system. The liver periphery seems to present some special characteristics that are not well known. For instance, some wound healing caused by esophageal varices in patients infected with Schistosoma mansoni exhibit a regenerative process similar to post-necrotic cirrhosis only in the liver periphery (Andrade 1967). Chagraoui et al. (2003) have described an association between hematopoietic and mesenchymal cells in the liver, but they have not analyzed the ECM of the liver; this aspect deserves further investigation in order to improve our understanding of its contribution to the proliferation and differentiation of several hematopoietic lineages in vivo and the formation of a special environment for hematopoiesis.

Mature or immature neutrophils depart from the liver when the environment is no longer favorable to them, migrating to other suitable environments through the circulation (intravasation and extravasation). Papayannopoulou and Craddock (1997) have shown that hematopoietic cells injected into mice are not specifically taken up by bone marrow but occur in the circulation and are widely spread in many organs such as the liver, lungs, kidneys, spleen, and bone marrow. Subsequently, blood cells are seen in the spleen and bone marrow, indicating a retention and proliferation of these cells in such niches. Hematopoietic stem cells in mouse fetal liver double in number daily from 12.5 to 
Fig. 11 Mouse liver at $0 \mathrm{dpp}$. a Marked decrease in the erythroid lineage (white arrow) with a few limited proliferative foci. HE stain. Bar $30 \mu \mathrm{m}$. Insert in a Presence of myeloid cells in the subcapsular region and of vacuolated hepatocytes. HE stain. Bar $20 \mu \mathrm{m}$. b Myeloid proliferative focus (white star) in the connective tissue of the portal space. Masson's trichrome stain. c Reticular fibers forming a three-dimensional network in the parenchyma and capsular regions (arrows). Gomori's reticulin stain. Bar $30 \mu \mathrm{m}$. d PAS reaction showing glycoproteins in the hepatocytes and delineating hepatocyte vacuolizations. PAS-AB $\mathrm{pH} 1.0$ stain. Bar $30 \mu \mathrm{m}$. e Fibronectin showing a granular pattern in the venula wall and sinusoids (green AlexaFluor488, blue Evans Blue, red DAPI). Bar $30 \mu \mathrm{m}$. f MMP-1 expression in the cytoplasm of neutrophils (green AlexaFluor488, blue Evans Blue, red DAPI). Bar $30 \mu \mathrm{m}$
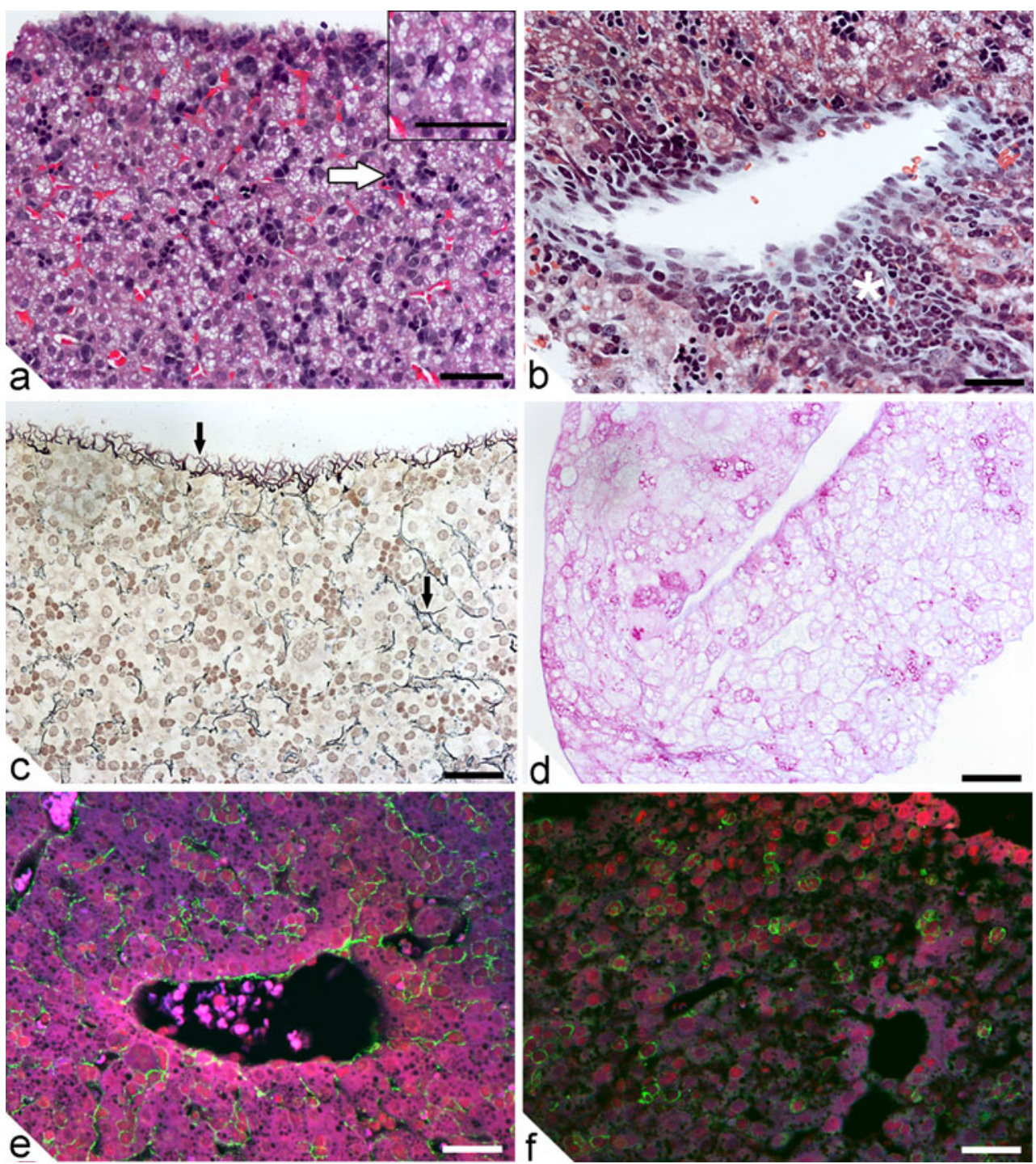

$14.5 \mathrm{dpc}$ but then decrease in number at 15.5 (Ikuta and Weissman 1992; Morrison et al. 1995). On days 13 and 14 dpc, the fetal liver ( $+/+$ or $+/$ Sl mouse) contains 1,200 and 2,300 Thy-1 ${ }^{\text {lo }}$ Lin $^{-} \mathrm{Sca}-1^{+}$cells, respectively, at a relatively constant percentage of $0.03 \%$ (Ikuta and Weiss- man 1992). At $15 \mathrm{dpc}$, the cells reach 5,100. However, rather then doubling to 10,200 by $16 \mathrm{dpc}$, only 4,350 fetal liver hematopoietic stem cells have been found. The rest of the expected cells occur in the circulation for progressive settling in the spleen and bone marrow (Christensen et al. 2004).
Fig. 12 a Negative control with anti-rabbit AlexaFluor488 (cartilage). b Negative MMP-9 expression in the fetal liver at 17 dpc. Bars $30 \mu \mathrm{m}$
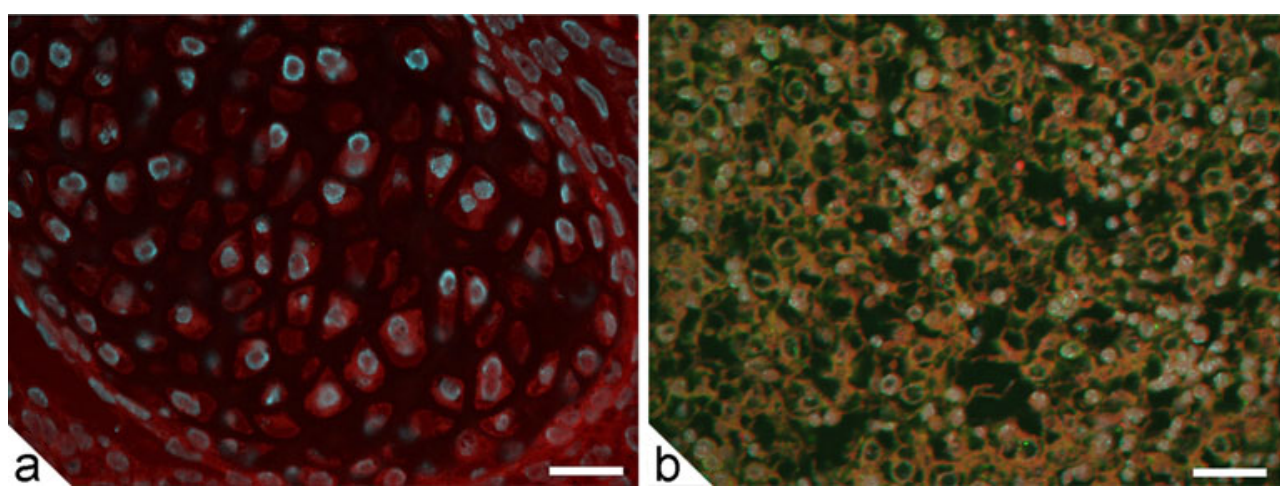
Table 1 Summary of extracellular matrix components in the murine fetal liver from 12 days post-coitum $(d p c)$ to 0 day post-partum $(d p p)$, showing some markers of liver maturity (PAS Periodic Acid Schiff staining, $M M P$ matrix metalloproteinase). The intensity of each element was scored from + to ++++ or as Negative

\begin{tabular}{llllll}
\hline Development age & Fibronectin & Reticulin fibers & PAS (hepatocytes) & MMP-1 & MMP-9 \\
\hline $12 \mathrm{dpc}$ & + (granular) & + & + & + (erythroid) & $+($ erythroid) \\
& & & & $+($ endothelium $)$ & $+++($ endothelium) \\
$13 \mathrm{dpc}$ & + + (linear) & + & ++ & $-($ endothelium) & $+($ endothelium) \\
& & & & Negative & Negative \\
$14 \mathrm{dpc}$ & +++ (trabecular) & Negative & ++ & Negative & Negative \\
$15 \mathrm{dpc}$ & ++ (trabecular) & Negative & +++ & Neutrophils & Negative \\
$16 \mathrm{dpc}$ & ++ (trabecular) & Negative & ++++ & Neutrophils & Negative \\
$17 \mathrm{dpc}$ & +++ (trabecular/ vascular) & Negative & ++++ & Neutrophils & Negative \\
$18 \mathrm{dpc}$ & +++ (trabecular/ vascular) & + & ++++ & Neutrophils & Negative \\
$0 \mathrm{dpp}$ & +++ (trabecular/ vascular) & +++ & +++ & &
\end{tabular}

Hence, the stem cell decrease in the fetal liver at $15.5 \mathrm{dpc}$ seems to be a consequence of hepatocyte differentiation (Kinoshita et al. 1999; Christensen et al. 2004).

The expression of MMP-1 is weak in the fetal liver endothelium and erythroid lineage at $12 \mathrm{dpc}$, becoming higher in erythroid cells at $13 \mathrm{dpc}$. Mature neutrophils from $16 \mathrm{dpc}$ to $0 \mathrm{dpp}$ always express MMP-1 with a high intensity. Khanna-Gupta et al. (2005) have verified that human neutrophil collagenase is one of the proteins in the secondary granules of late granulocytic cells, whereas MMP-9 has been detected only in the liver endothelium and erythroid cells in the immature liver (12 and $13 \mathrm{dpc})$, being completely negative after $15 \mathrm{dpc}$. These results reveal that both MMP-1 and MMP-9 contribute to the beginning of erythropoiesis, but the mechanisms involved are still unknown. Robinson et al. (2005) have shown that MMP-9 is not required for erythropoietin and granulocyte colonystimulating factor (G-CSF) mobilization. On the other hand, Heissig et al. (2002) have confirmed that MMP-9 promotes the release of the cell-soluble Kit ligand (SkitL) by bone marrow, a ligand that favors the homing of endothelial and hematopoietic cells from quiescent to proliferative niches. MMPs not only induce the break-up of ECM molecules, but also allow the release of cytokines (Vu and Werb 2000), such as the vascular endothelial growth factor, which might play a role in angiogenesis (Bergers et al. 2000) and osteoblast recruitment (Engsig et al. 2000). In contrast, MMP and TIMP (tissue inhibitor of MMP) play other roles, acting as growth factors and removing cellular receptors (Guedez et al. 1996). Many other investigations have demonstrated that TIMP-1 and -2 have many functions such as anti-protease activity and as growth factors, acting as enhancers of the erythroid lineage (Docherty et al. 1985; Hayakawa et al. 1990; Stetler-Stevenson et al. 1992; Chesler et al. 1995). Krane (1995) have described a physiological function of MMP-1 in bone remodeling. In addiction, neutrophils are reported to express MMP-1 in chronic obstructive lung disease (Cawston et al. 2001) and in inflammatory reactions in dentary pulp lesions (Shin et al. 2002). MMP-1 might also play a role in destroying or disturbing the basal membrane of the vessels during cell diapedesis, especially in the migration from fetal liver to bone marrow during ontogeny, with a similar mechanism of metastatic homing (Brinckerhoff et al. 2000; Yana and Seiki 2002; Seiki 2003; Seiki and Yana 2003; Pardo and Selman 2005).
Table 2 Semiquantified analysis of three hematopoietic lineages present in the murine fetal liver during embryogenesis. The presence of each lineage was scored from + to ++++

\begin{tabular}{llll}
\hline Development age & Erythroid & Megakaryocytic & Myeloid \\
\hline $12 \mathrm{dpc}$ & ++++ & ++++ & + \\
$13 \mathrm{dpc}$ & ++++ & ++++ & + \\
$14 \mathrm{dpc}$ & ++++ & +++ & ++ \\
$15 \mathrm{dpc}$ & +++ & +++ & +++ \\
& & & (with eosinophils) \\
$16 \mathrm{dpc}$ & +++ & +++ & ++++ \\
$17 \mathrm{dpc}$ & +++ & ++ & ++++ \\
$18 \mathrm{dpc}$ & ++ & ++ & ++ \\
$0 \mathrm{dpp}$ & + & + & + \\
\hline
\end{tabular}


The diffusion of hematopoietic cells during ontogenetic development makes use of similar processes as inflammatory, tumor, and fungal cell spreading, all of which present the following: (1) a primary source (stem cell, primary tumor or focus), (2) local proliferation, (3) detachment from the primary source, (4) intravasation, (5) intravascular motility, (6) extravasation, (7) entrance to the organ parenchyma, (8) metastatic or metastatic-like proliferation influenced by paracrine growth factors, (8) repetition of the cycle from step 3 (De Vita et al. 2004; Mendes-Giannini et al. 2000).

In conclusion, the intensity and location of hematopoietic lineages change during the process of fetal liver maturation. We have been able to correlate the myeloid lineage with the mesenchymal stroma (around portal vessel walls and subcapsules) and erythroid development with the endodermal stroma (hepatocytes).

Acknowledgements We express our thanks to Luzia Caputo, Alexandra Menezes, Luzia Barros, Luciana Souza, and Marcella Branças for technical assistance with the histology and also to Iolanda Deolinda and Andréa Natividade for help with the breeding of the mice. We are grateful to Bernardo Pascarelli for technical assistance with the confocal microscopy and to Rodrigo Mexas (Image Production and Treatment Facility) for help with image processing.

Open Access This article is distributed under the terms of the Creative Commons Attribution Noncommercial License which permits any noncommercial use, distribution, and reproduction in any medium, provided the original author(s) and source are credited.

\section{References}

Amenta PS, Harrison D (1997) Expression and potential role of the extracellular matrix in hepatic ontogenesis: a review. Microsc Res Tech 39:372-386

Andrade ZA (1967) Esquistosomiasis hepática: aspectos morfológicos. In: Popper H, Schaffner F (eds) Progresos en patología hepática, vol II. Editorial Científico Médica, Barcelona, pp 249 264

Arias MA, Stewart A (2002) Molecular principles of animal development. Oxford University Press, Oxford

Bergers $\mathrm{G}$, Brekken R, McMahon G, Vu TH, Itoh T, Tamaki K, Tanzawa K, Thorpe P, Itohara S, Werb Z, Hanahan D (2000) Matrix metalloproteinase- 9 triggers the angiogenic switch during carcinogenesis. Nat Cell Biol 2:737-744

Bogomoletz W (1980) Advantages of the Sirius red staining method for amyloid and eosinophils. Arch Anat Cytol Pathol 28:252-253

Brill S, Zvibel I, Halpern Z, Oren R (2002) The role of fetal and adult hepatocyte extracellular matrix in the regulation of tissue-specific gene expression in fetal and adult hepatocytes. Eur J Cell Biol 81:43-50

Brinckerhoff CE, Rutter JL, Benbow U (2000) Interstitial collagenases as markers of tumor progression. Clin Cancer Res 6:4823-4830

Carson FL, Martin JH, Lynn JA (1973) Formalin fixation for electron microscopy: a re-evaluation. Am J Clin Pathol 59:365-373

Cawston T, Carrere S, Catterall J, Duggleby R, Elliott S, Shingleton B, Rowan A (2001) Matrix metalloproteinases and TIMPs: proper- ties and implications for the treatment of chronic obstructive pulmonary disease. Novartis Found Symp 234:205-218

Chagraoui J, Lepage-Noll A, Anjo A, Uzan G, Charbord P (2003) Fetal liver stroma consists of cells in epithelial-to-mesenchymal transition. Blood 101:2973-2982

Chesler L, Golde DW, Bersch N, Johnson MD (1995) Metalloproteinase inhibition and erythroid potentiation are independent activities of tissue inhibitor of metalloproteinases-1. Blood 86:4506-4015

Christensen JL, Wright DE, Wagers AJ, Weissman IL (2004) Circulation and chemotaxis of fetal hematopoietic stem cells. PLoS Biol 2:0368-0377

Craddock CF, Nakamoto B, Elices M, Papayannopoulou T (1997) The role of CS1 moiety of fibronectin in VLA4-mediated haemopoietic progenitor trafficking. Br J Haematol 97:15-21

Cumano A, Godin I (2001) Pluripotent hematopoietic stem cell development during embryogenesis. Curr Opin Immunol 13:166-171

De Vita VT Jr, Hellman S, Rosenberg S (2004) Principles and practice of oncology, 7th edn. Lippincott Williams \& Wilkins, Philadelphia

Docherty AJ, Lyons A, Smith BJ, Wright EM, Stephens PE, Harris TJ, Murphy G, Reynolds JJ (1985) Sequence of human tissue inhibitor of metalloproteinases and its identity to erythroidpotentiating activity. Nature 318:66-69

Dzierzak E (1999) Embryonic beginnings of definitive hematopoietic stem cells. Ann NY Acad Sci 872:256-262

Dzierzak E, Medvinsky A (1995) Mouse embryonic hematopoiesis. Trends Genet 11:359-366

Emura I, Sekiya M, Ohnishi Y (1983) Two types of progenitors of the granulocyte series in the human embryonic liver. Arch Histol Jpn 46:229-242

Engsig MT, Chen QJ, Vu TH, Pedersen AC, Therkidsen B, Lund LR, Henriksen K, Lenhard T, Foged NT, Werb Z, Delaissé JM (2000) Matriz metalloproteinase-9 and vascular endothelial growth factor are essential for osteoclast recruitment into developing long bones. J Cell Biol 151:879-890

Enzan H, Takahashi H, Kawakami M, Yamashita S, Ohkita T (1978) Light and electron microscopic observations on hepatic hematopoiesis of human fetuses. I. Granulocytopoiesis in the hepatic mesenchymal tissue. Acta Pathol Jpn 28:411-426

Gualdi R, Bossard P, Zheng M, Hamada Y, Coleman JR, Zaret KS (1996) Hepatic specification of the gut endoderm in vitro: cell signaling and transcriptional control. Genes Dev 10:1670-1682

Guedez L, Lim MS, Stetler-Stevenson WG (1996) The role of metalloproteinases and their inhibitors in hematological disorders. Crit Rev Oncog 7:205-225

Hamada T, Möhle R, Hesselgesser J, Hoxie J, Nachman RL, Moore MA, Rafii S (1998) Transendothelial migration of megakaryocytes in response to stromal cell-derived factor 1 (SDF-1) enhances platelet formation. J Exp Med 188:539-548

Hayakawa T, Yamashita K, Kishi J, Harigawa K (1990) Tissue inhibitor of metalloproteinases from human bone marrow stroma cell line KM 102 has erythroid-potentiating activity, suggesting its possibly bifunctional role in the hematopoietic microenvironment. FEBS Lett 268:125-128

Heissig B, Hattori K, Dias S, Friedrich M, Ferris B, Hackett NR, Crystal RG, Besmer P, Lyden D, Moore MA, Werb Z, Rafii S (2002) Recruitment of stem cells from the bone marrow niche requires MMP-9 mediated release of Kit-Ligand. Cell 109:625-637

Houssaint E (1980) Differentiation of the mouse hepatic primordium. I. An analysis of tissue interactions in hepatocyte differentiation. Cell Differ 9:269-279

Ikuta K, Weissman IL (1992) Evidence that hematopoietic stem cells express mouse c-kit but do not depend on steel factor for their generation. Proc Natl Acad Sci USA 89:1502-1506

Kaufman MH (1992) The atlas of mouse development. Academic Press, London 
Khanna-Gupta A, Zibello T, Idone V, Sun H, Lekstrom-Himes J, Berliner N (2005) Human neutrophil collagenase expression is C/ERP-dependent during myeloid development. Exp Hematol $33: 42-52$

Kinoshita T, Miyajima A (2002) Cytokine regulation of liver development. Biochim Biophys Acta 1592:303-312

Kinoshita T, Sekiguchi T, Xu MJ, Ito Y, Kamiya A, Tsuji K, Nakahata T, Miyajima A (1999) Hepatic differentiation induced by oncostatin $\mathrm{M}$ attenuates fetal liver hematopoiesis. Proc Natl Acad Sci USA 96:7265-7270

Krane SM (1995) Is collagenase (matrix metalloproteinase-1) necessary for bone and other connective tissue remodeling? Clin Orthop Relat Res 313:47-53

Lane WJ, Dias S, Hattori K, Heissig B, Choy M, Rabbany SY, Wood J, Moore MA, Rafii S (2000) Stromal-derived factor 1-induced megakaryocyte migration and platelet production is dependent on matrix metalloproteinases. Blood 96:4152-4159

Lennert K (1978) Malignant lymphomas other than Hodgkin's disease. Springer, Berlin

Lenzi HL, Lenzi JA (1986) Ontogeny of the lymphohamatopoietic and lymphoid tissues in human fetuses - the four sequential phases. Braz J Med Biol Res 19:666A

Luque EH, Montes GS (1989) Progesterone promotes a massive infiltration of the rat uterine cervix by the eosinophilic polymorphonuclear leukocytes. Anat Rec 223:257-265

Mendes-Giannini MJ, Taylor ML, Bouchara JB, Burger E, Calich VL, Escalante ED, Hanna SA, Lenzi HL, Machado MP, Miyaji M, Monteiro Da Silva JL, Mota EM, Restrepo A, Restrepo S, Tronchin G, Vincenzi LR, Xidieh CF, Zenteno E (2000) Pathogenesis II: fungal responses to host responses: interaction of host cells with fungi. Med Mycol 38 (Suppl 1):113-123

Morrison SJ, Hemmati HD, Wandycz AM, Weissman IL (1995) The purification and characterization of fetal liver hematopoietic stem cells. Proc Natl Acad Sci USA 92:10302-10306

Papayannopoulou T, Craddock C (1997) Homing and trafficking of hemopoietic progenitor cells. Acta Haematol 97:97-104

Pardo A, Selman M (2005) MMP-1: the elder of the family. Int J Biochem Cell Biol 37:283-288

Quondamatteo F, Knittel T, Mehde M, Ramadori G, Herken R (1999a) Matrix metalloproteinases in early human liver development. Histochem Cell Biol 112:277-282

Quondamatteo F, Scherf C, Miosge N, Herken R (1999b) Immunohistochemical localization of laminin, nidogen, and type IV collagen during the early development of human liver. Histochem Cell Biol 111:39-47

Robinson SN, Seina SM, Gohr JC, Sharp JG (2005) Hematopoietic progenitor cell mobilization by granulocyte colony-stimulating factor and erythropoietin in the absence of matrix metalloproteinase-9. Stem Cells Dev 14:317-328

Sánchez A, Alvarez AM, Pagan R, Roncero C, Vilaró S, Benito M, Fabregat I (2000) Fibronectin regulates morphology, cell organization and gene expression of rat fetal hepatocytes in primary culture. J Hepatol 32:242-250

Seiki M (2003) Membrane-type 1 matrix metalloproteinase: a key enzyme for tumor invasion. Cancer Lett 194:1-11

Seiki M, Yana I (2003) Roles of pericellular proteolysis by membrane type-1 matrix metalloproteinase in cancer invasion and angiogenesis. Cancer Sci 94:569-574

Shin SJ, Lee JI, Baek SH, Lim SS (2002) Tissue levels of matrix metalloproteinases in pulps and periapical lesions. J Endod 28:313-315

Sohn DS, Kim KY, Lee WB, Kim DC (1993) Eosinophilic granulopoiesis in human fetal liver. Anat Rec 235:453-460

Stetler-Stevenson WG, Bersh N, Golde DW (1992) Tissue inhibitor of metalloproteinase-2 (TIMP-2) has erythroid-potentiating activity. FEBS Lett 296:231-234

Thomas DB, Yoffey JM (1964) Human foetal haematopoiesis. II. Hepatic haematopoiesis in the human foetus. $\mathrm{Br} \mathrm{J}$ Haematol 10:193-197

Unsworth DJ, Scott DL, Almond TJ, Beard HK, Holborow EJ, Walton KW (1982) Studies of reticulin I: serological and immunohistological investigation of the occurrence of collagen type III, fibronectin and the non-collagenous glycoprotein of Pras and Glynn in reticulin. Br J Exp Pathol 63:154-166

$\mathrm{Vu} \mathrm{TH}$, Werb Z (2000) Matrix metalloproteinases: effectors of development and normal physiology. Genes Dev 14:2123-2133

Yana I, Seiki M (2002) MT-MMPs play pivotal roles in cancer dissemination. Clin Exp Metastasis 19:209-215

Zamboni L (1965a) Electron microscopic studies of blood embryogenesis in humans. I. The ultrastructure of the fetal liver. J Ultrastruct Res 12:509-524

Zamboni L (1965b) Electron microscopic studies of blood embryogenesis in humans. II. The hemopoietic activity in the fetal liver. J Ultrastruct Res 12:525-541

Zaret KS (2002) Regulatory phases of early liver development: paradigms of organogenesis. Nat Rev Genet 3:499-512 